\title{
TU/e EmonONEN

\section{An indirect method to assess wrist ligament forces with particular regard to the effect of preconditioning}

\section{Citation for published version (APA):}

Savelberg, H. H. C. M., Kooloos, J. G. M., Huiskes, H. W. J., \& Kauer, J. M. G. (1993). An indirect method to assess wrist ligament forces with particular regard to the effect of preconditioning. Journal of Biomechanics, 26(11), 1347-1351. https://doi.org/10.1016/0021-9290(93)90358-L

DOI:

10.1016/0021-9290(93)90358-L

Document status and date:

Published: 01/01/1993

\section{Document Version:}

Publisher's PDF, also known as Version of Record (includes final page, issue and volume numbers)

\section{Please check the document version of this publication:}

- A submitted manuscript is the version of the article upon submission and before peer-review. There can be important differences between the submitted version and the official published version of record. People interested in the research are advised to contact the author for the final version of the publication, or visit the $\mathrm{DOI}$ to the publisher's website.

- The final author version and the galley proof are versions of the publication after peer review.

- The final published version features the final layout of the paper including the volume, issue and page numbers.

Link to publication

\section{General rights}

Copyright and moral rights for the publications made accessible in the public portal are retained by the authors and/or other copyright owners and it is a condition of accessing publications that users recognise and abide by the legal requirements associated with these rights.

- Users may download and print one copy of any publication from the public portal for the purpose of private study or research.

- You may not further distribute the material or use it for any profit-making activity or commercial gain

- You may freely distribute the URL identifying the publication in the public portal.

If the publication is distributed under the terms of Article 25fa of the Dutch Copyright Act, indicated by the "Taverne" license above, please follow below link for the End User Agreement:

www.tue.nl/taverne

Take down policy

If you believe that this document breaches copyright please contact us at:

openaccess@tue.nl

providing details and we will investigate your claim. 


\title{
AN INDIRECT METHOD TO ASSESS WRIST LIGAMENT FORCES WITH PARTICULAR REGARD TO THE EFFECT OF PRECONDITIONING
}

\author{
H. H. C. M. SavelberG, ${ }^{*}$ J. G. M. Kooloos, ${ }^{*}$ R. Huiskes $†$ and J. M. G. KaUeR* \\ *Department of Anatomy and Embryology; $\uparrow$ Institute of Orthopaedics, University of Nijmegen, \\ The Netherlands
}

\begin{abstract}
A method has been developed to calculate the forces that are developed in the ligaments of a joint specimen during motions. This indirect method is needed since direct measurements fail in the case of small ligaments. As an example the small ligaments of the carpal joint are considered. The rationale of the method is that the force generated in a ligament depends on the amount of strain to which it is subjected and on its material characteristics. In the method presented the lengths of the ligaments are determined in vitro at several joint positions by means of röntgenstereophotogrammetry. The zero-force length and the force-elongation relationship are determined on the same ligaments isolated in a materials testing machine.

Over a considerable part of the strain range the measurement errors are relatively small compared to the forces determined, less than $10 \%$. The method is applicable to joints in situations where other measuring methods cannot be used. The present analysis shows, however, that the force values determined are susceptible to preconditioning of the ligaments. In preconditioned ligaments the forces could be up to $50 \%$ lower than in the non-preconditioned situation. This suggests that ligament forces may vary considerably in vivo, depending on the extent of preconditioning provoked by a particular function.
\end{abstract}

\section{INTRODUCTION}

The in vitro measurements of ligament forces are subject to a number of problems. In many joints the ligaments are small and not easily accessible for relatively large measuring devices, e.g. buckle transducers. The problems with these devices include impingement with the bones and ligament shortening due to the installation of the device and the effect of preconditioning. Although the design of buckle-type transducers has been improved several times (An et al., 1990; Barry and Ahmed, 1986; Lewis et al., 1982), the interference with the surrounding structures remains a problem for small joints, such as the wrist. The same can be said for a recently developed implantable force transducer (Cummings et al., 1991; Xu et al., 1990). Takai et al. (1991) determined kneeligament forces individually, based on kinematic data obtained from the intact joint and load-elongation data determined after dissection. With this method the application of mechanical devices to the knee-joint ligaments is avoided.

Viidik $(1973,1980)$ showed that due to the viscoelastic nature of ligaments, the load-deformation curve stabilizes after a few loading cycles. In this stable situation, there is an increase in laxity compared to the initial response with the implication that the unloaded length has increased. Hence, to obtain reproducible and interindividually comparable force-elongation curves, it is necessary in material testing procedures to precondition the ligaments (Butler et al., 1978; Fung, 1972; Viidik, 1973; Woo et al., 1983, 1986).

The present paper describes a non-invasive method as it is applied to ligaments of a wrist joint, and reports on the accuracy of the method and on the effects of preconditioning on the forces estimated.

First received 19 June 1991; accepted 4 January 1993.

Address correspondence to: Prof. Dr J. M. G. Kauer, Dept Anatomy and Embryology, University of Nijmegen, P.O. Box 9101, 6500 HB Nijmegen, The Netherlands.

\section{METHODS}

The method to estimate ligament-force patterns consists of three stages: (i) the determination of ligament length in several positions of the joint, (ii) the determination of the zero-force length of the ligament and (iii) the recording of the force-elongation relationships for the ligaments.

In this study the röntgenstereophotogrammetric analysis (RSA) method to determine the three-dimensional position of markers (Selvik, 1974, 1989) is used. This method has been developed further by de Lange et al. (1990) to enable the measurements of ligament length and ligament-length changes in the wrist joint. Depending on the width of a ligament, the ligaments are provided with one or two strings of radio-opaque markers (tantalum pellets; diameter: $0.5 \mathrm{~mm}$ ). Very small incisions were made in the ligaments to create small envelopes to contain the markers. After the pellets were inserted, each of these envelopes were covered by a dot of tissue glue (Histoacryl ${ }^{\text {Do }}$, Brown AG; Melsungen, FRG) to prevent the markers from being squeezed out of the ligaments. Since these incisions and the dots of tissue glue are small relative to ligament dimensions, the effects of applying markers to the ligaments are assumed to be negligible. The ligament length is represented by the summation of subsequent marker intervals. In the present study, four superficial ligaments (RCP, RLP, TCP and RTD) of one fresh cadaver wrist-joint specimen are provided with pellets (de Lange et al., 1990; Savelberg et al., 1991). The RLP ligament, which is a relatively wide ligament, is marked with two strings of pellets, a proximal (RLPp) and a distal one (RLPd). After this preparation the specimen is positioned, in full supination, into a motion constraining device (de Lange et al., 1985) in which the flexion or deviation angle between the hand and the forearm can be controlled.

At different deviation and flexion angles, pairs of stereo radiographs are made. From the stereo radiographs the three-dimensional position of the markers can be reconstructed and the ligament lengths $(L)$ can be calculated at each 
position of the joint (de Lange et al., 1990; Savelberg et al. 1991).

After the in vitro RSA experiments, the specimens are partitioned in bone-ligament-bone (BLB) preparations (Savelberg et al., 1992). Each BLB-preparation corresponds to one of the ligaments or ligament parts marked and considered in the in vitro RSA experiment. The isolated ligaments and the bony parts still contain the markers which are provided to them for the in vitro RSA experiments.

The BLB preparations are then placed in a slack position in a tensile testing machine (MTS, Berlin, Germany). The ligament fibres are aligned with the load axis of the testing machine as accurately as possible.

From the slack position the ligament is elongated until it starts to generate a small amount of force $(0.25 \mathrm{~N})$. This is detected by a load cell (MTS, Berlin, Germany) to which one of the bony parts of the BLB specimen is connected. An additional pair of stereo radiographs is made in this position. From this pair of radiographs the zero-force length of the ligament $\left(L_{\mathrm{ZF}}\right)$ is calculated.

Immediately after the stereo radiographs for the zero-force length determinations have been made, the ligaments are subjected to cyclic tensile tests. In the tensile testing machine the BLB preparations are stretched 25 times to $15 \%$ of their initial lengths at a rate of $66 \%$ of the initial lengths. For this purpose, the initial length is determined by a pair of vernier callipers before the ligament is positioned in the tensile testing machine. During the tensile test the ligament force, registered by the load cell, is sampled at a rate of $200 \mathrm{~Hz}$ and stored in a personal computer. Strain of $15 \%$ in wrist-joint ligaments equals a situation in which the linear part of the force-elongation curve has been reached without introducing permanent deformations to the ligament.

Because the ligament alignment procedure can only be controlled visually, it is not very precise, and is repeated three times. The test resulting in the highest stiffness characteristics of the three is then chosen for further processing. A period of at least half an hour is allowed between the three tests so that the ligament can recover. The specimens were kept in saline-soaked tissues to prevent them from drying, except that during the tensile tests they were not protected.

A second-degree polynomial equation is fitted to the force-elongation data points of the first loading cycle, when the ligaments are not preconditioned. A similar polynomial equation is calculated for the data points of the last five loading cycles, when the ligaments are preconditioned. The polynomial equation is of the form

$$
F=a L^{2}+b L+c,
$$

where $a, b$ and $c$ are constants, $F$ is the force $(\mathrm{N})$ developed in the ligament and $L$ is the elongation of the ligament $(\mathrm{mm})$.

When the ligament is preconditioned, force develops only after the ligament has been strained several percent; hence, the force-elongation curve shifts to the right. This implies that its zero-force length has increased somewhat. The preconditioned zero-force length is then estimated from the force-elongation measurement sampling points, taking the first point for which the force is greater than zero as the zero-force length. This value is less well defined than the one determined in the procedure for the first loading cycle. HowEver, it was shown that smail variations hardiy affect the constants in the polynomial fit.

To calculate the forces that a ligament generates in a position $p$ of the hand $[F(p)]$, the effective elongation $[E L(p)]$ in that position is calculated according to

$$
\mathrm{EL}(p)=L(p)-L_{\mathrm{ZF}}
$$

where $L(p)$ is the in vitro length of the ligament determined in the RSA experiment, with the hand in position $p$, and $L_{\mathrm{ZF}}$ is the zero-force length of the ligament in the non-preconditioned situation. By substituting the value of $\operatorname{EL}(p)$ for $L$ into the quadratic polynomial equation (1) the force developed by the ligament in that given position of the hand is calculated. The forces are plotted against the position of the hand, giving ligament force patterns.

The accuracy of this method for estimating the force developed in a ligament may be affected by several factors, including the precision of the in vitro ligament length determination, the precision of the measurement of the zero-force length, and the fit of the quadratic polynomial equation.

The accuracy of the in vitro ligament length depends on the accuracy of the RSA method, i.e. the precision of the three-dimensional reconstruction of the markers. Savelberg et al. (1991) found that the standard deviation for the determination of carpal ligament lengths with four or five markers ranged between 0.005 and $0.055 \mathrm{~mm}$. This standard deviation will be referred to in this paper as $\sigma L$.

The variations in the zero-force length measurement can also be attributed to errors in the three-dimensional recon. struction of the markers. Hence, the standard deviation for the zero-force length determination $\left(\sigma L_{\mathrm{ZF}}\right)$ equals that for the in vitro ligament length measurement $(\sigma L)$.

The standard deviation of the effective elongation $(\sigma \mathrm{EL})$ is calculated according to

$$
\sigma E L=\left(\sigma L^{2}+\sigma L_{\mathrm{ZF}}^{2}\right)^{1 / 2}
$$

The accuracy of the force-elongation relationship $\left(r^{2}\right)$, which is represented by the second-degree polynomial equation, is calculated by the sum of squares approach for the differences between the sampled force measurements and the forces calculated by the polynomial equation, according to

$$
r^{2}=\frac{1}{n} \sum_{i=1}^{n}\left[F_{i}(\mathrm{EL})-\hat{F}_{i}(\mathrm{EL})\right]^{2}
$$

where $F_{i}(E L)$ is the force calculated by the polynomial equation for a given effective elongation $(E L), \hat{F}_{i}(E L)$ is the force measured in the tensile testing machine at the same effective elongation (EL), and $n$ is the number of force samples to which the quadratic polynomial equation is fitted. Hence, this value $r^{2}$ gives the amount of variance of the force which cannot be explained by the polynomial equation. It is inversely proportional to the goodness of the fit. Using rules for error propagation, the standard deviation for the force calculated at a certain position of the hand $(\sigma F)$ can be obtained from

$$
\sigma F(p)=\left\{\sigma \mathrm{EL}^{2}[2 a \mathrm{EL}(p)+b]^{2}+r^{2}\right\}^{1 / 2}
$$

where $\sigma F(p)$ is the standard deviation of the force developed by a ligament with the hand in position $p, \sigma \mathrm{EL}$ is the standard deviation for the calculation of the effective elongation of the ligament, $a$ and $b$ are the constants of the quadratic polynomial equation describing the force-elongation relationship, EL( $p)$ is the effective elongation of the ligament at position $p$ of the hand and $r^{2}$ is the sumof-squares approach representing the goodness of fit of the quadratic polynomial equation to the force samples.

\section{RESULTS}

For the case where the alignment error in the determination of $L$ is neglected, the value for $\sigma L$ is considered to be $0.055 \mathrm{~mm}$, as indicated in the previous section. This value is the upper bound for this error as reported by Savelberg et al. (1991). The error made in the determination of the zero-force length is also assumed to be $0.055 \mathrm{~mm}$. Consequently, the accuracy for the effective elongation computation $(\sigma \mathrm{EL})$ is $0.078 \mathrm{~mm}$. The standard deviations for the force determinations $\left(\sigma F_{\max }\right)$ at the maximum strain applied in the material testing machine vary approximately between 2 and $6 \mathrm{~N}$ (Table 1). The forces which are calculated at these 'maximal' strains range from 39 to $115 \mathrm{~N}$. The quadratic polynomial equations for the effective lengthening-force relationships for each ligament or ligament part and their standard deviations prior to preconditioning of the ligaments are presented in Fig. 1A-E. 
RCP LIGAMENT

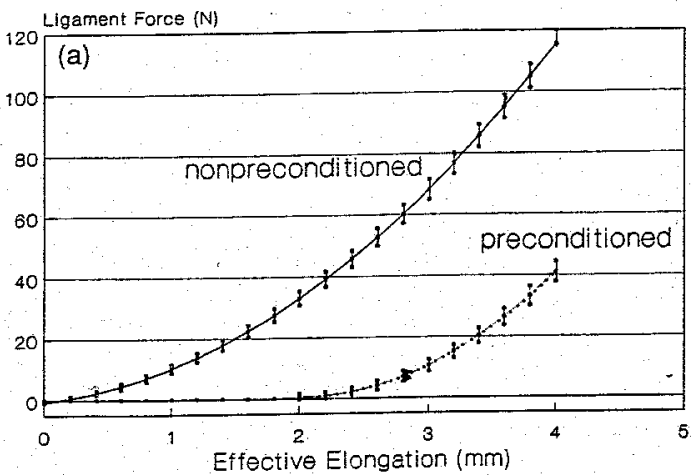

RLPp LIGAMENT

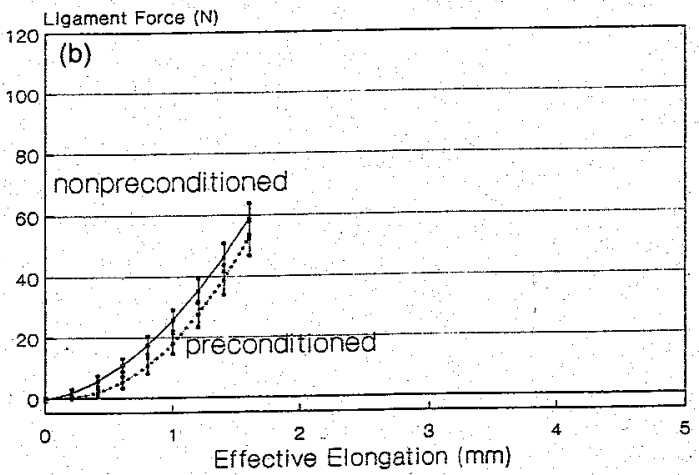

RLPd LIGAMENT

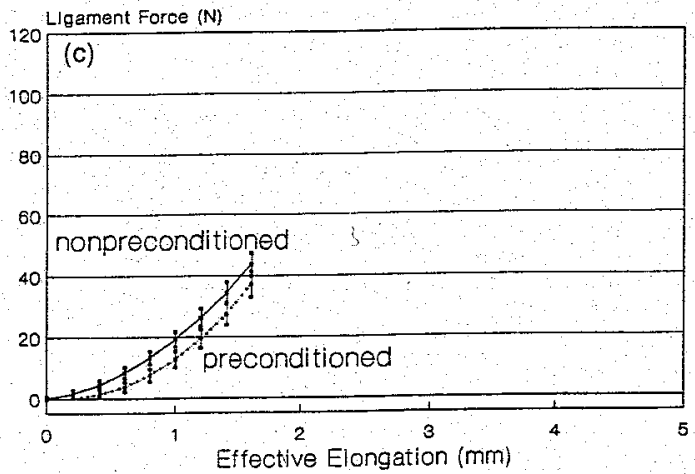

The error in the estimate of the ligament forces is the accumulation of two experimental errors: the error in the determination of the effective elongation $(\sigma \mathrm{EL})$ and the error in the fit of the polynomial equation to the force elongation. data points $\left(r^{2}\right)$. The contribution of $\sigma \mathrm{EL}$ depends furthermore on the current stiffness (the derivative of the quadratic polynomial equation at a given elongation) of the ligament. The contribution of the $r^{2}$ values to the final $\sigma F$ is small, maximally about $1.2 \mathrm{~N}^{2}$ (Table 1). In Fig. 2 the force samples and the calculated second-degree polynomial equation for the preconditioned RCP ligament are plotted to show the fit corresponding to the data points determined. Especially

\section{TCP LIGAMENT}

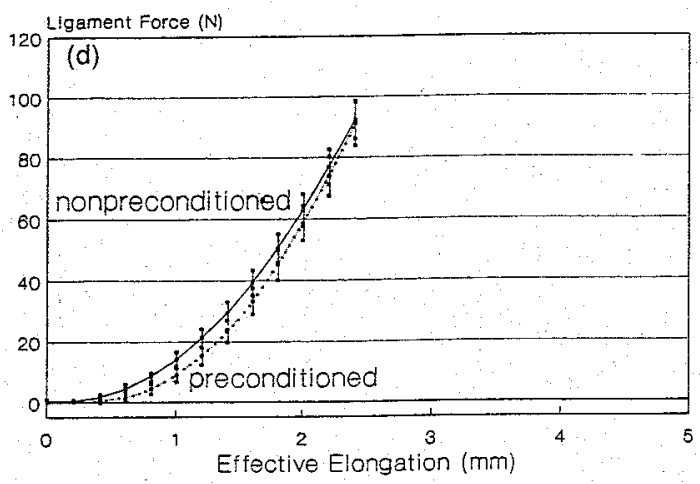

\section{RTD LIGAMENT}

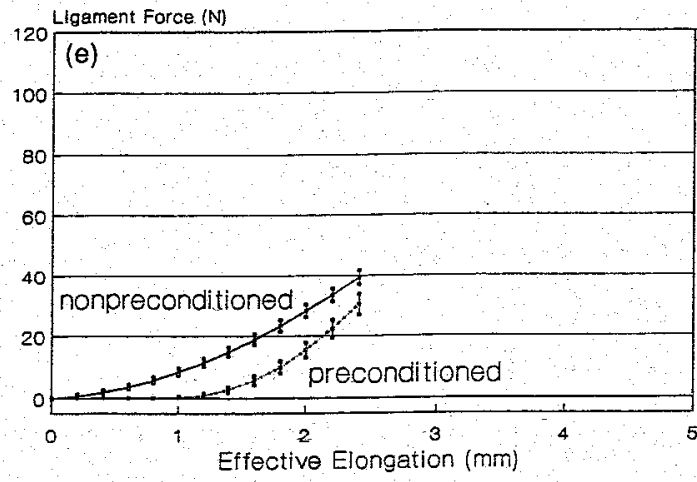

Fig. 1. The forces calculated for a range of effective elongations by the quadratic polynomial equations and their standard deviations for the five ligaments tested: (a) RCP, (b) RLPp, (c) RLPd, (d) TCP and (e) RTD. Curves for both the non-preconditioned and the preconditioned ligaments are presented in each figure. The effective-elongation ranges resemble the ones that were applied in the material testing machine. The estimated measurement errors, $\sigma L$, are given as dotted lines.

when the effective elongation increases, the relative contribution of $r^{2}$ to $\sigma F$ in equation (5) is of minor importance. The contribution of the error in the determination of the effective elongation is also of minor importance; for wrist-joint ligaments it is determined to be approximately $0.078 \mathrm{~mm}$. The main influence on the error in the force determination originates from the effective elongation. When the effective elongation increases, the current stiffness of the ligament, in equation (5) the component $[2 a \mathrm{EL}(p)+b]$, increases, and this resuits in a higher inaccuracy of the force determination.

Due to preconditioning the estimated forces in the ligaments decrease (Fig. 1(a)-(e)). This decrease of force is accompanied by an increase of the zero-force length in the preconditioned ligament. Hence, a ligament first starts to generate forces at higher elongation levels. For the ligaments tested the increases of the zero-force lengths range between 0.9 and $5.4 \%$ of the zero-force length as determined in the nonpreconditioned ligament.

For the purpose of demonstration of application of the method developed, effective elongation and force patterns are presented for the RTD ligament during flexion of the wrist joint (Fig. 3(a) and (b)). 


\section{POLYNOMIAL FIT LIGAMENT RCP}

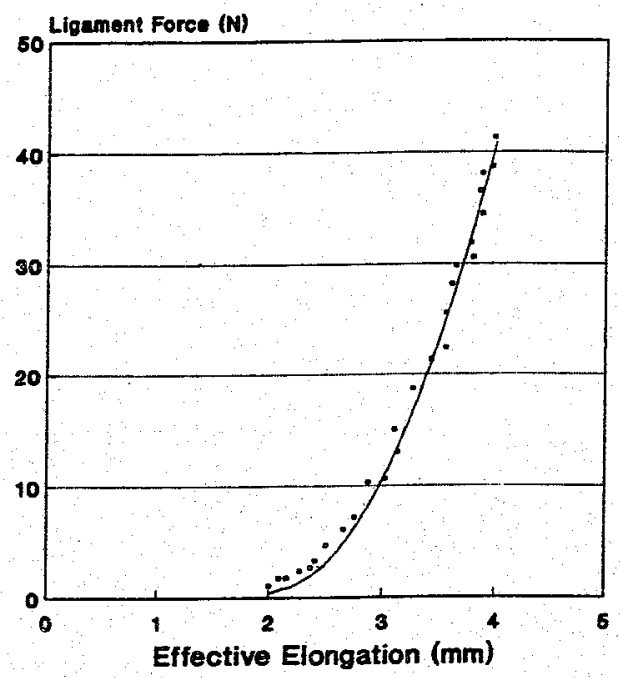

Fig. 2. The quadratic polynomial equations calculated for the effective-elongation force relationships of ligament RCP and the measured force samples.

\section{DISCUSSION}

The results of the accuracy determination show that the present method can determine forces in ligaments rather precisely. The advantage of this method over conventional techniques, like buckle-type transducers and implanted force transducers, is that it does not interfere with the anatomical parts of a joint, and therefore with its mobility. The extremely small pellets glued to the ligaments in the present study most probably do not have great influence on the measurements (de Lange et al., 1990). Furthermore, the dimension of the smallest structure to be considered is only limited by the size of the pellets, which can be as small as $0.5 \mathrm{~mm}$ in diameter. Hence, it is possible to consider the forces in different fibres in one ligament. A disadvantage of this method is that it cannot be applied in vivo.

A special problem that has to be dealt with is the question of whether or not the force-elongation curve should be determined from the non-preconditioned or from the preconditioned ligament. In order to obtain reproducible and

\section{EFFECTIVE ELONGATION LIGAMENT RTD FLEXION}

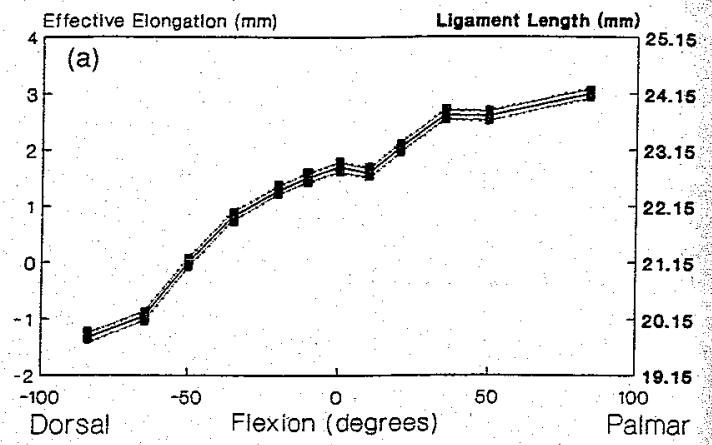

\section{LIGAMENT FORCE LIGAMENT RTD FLEXION}

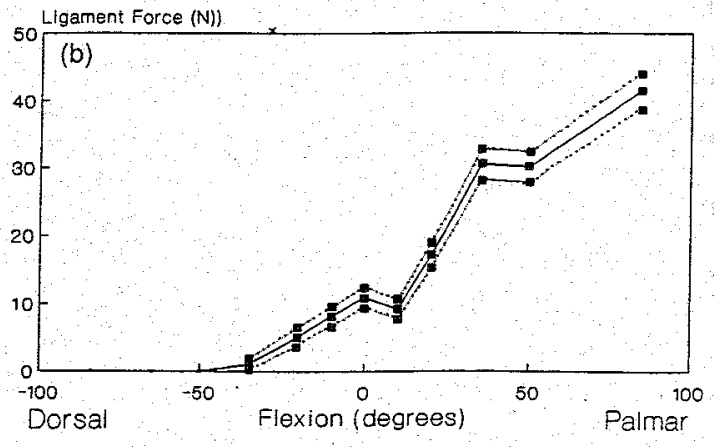

Fig. 3. The effective elongation pattern and the ligament length (a) and the force pattern (b) for the RTD ligament during flexion of the wrist joint. In Fig. 3(a) the dotted lines give the standard deviations for the determination of the effective elongation, $\sigma \mathrm{EL}$; in Fig. 3(b) the standard deviation for the estimation of the forces, $\sigma F$, are represented by dotted lines.

interindividually comparable force-elongation curves, it is a convention in material testing to precondition ligaments before material characteristics are determined (Butler et al., 1978; Fung, 1972; Viidik, 1973; Woo et al., 1983, 1986). Preconditioning is, however, not applied or mentioned in

Table 1. The ligament lengths in the neutral position of the hand ( $\left.L_{\text {NEurral }}\right)$, zero-force length $\left(L_{\mathrm{ZF}}\right)$, forces generated by the ligaments when maximally strained in the tensile testing machine $\left(F_{\max }\right)$, and standard deviations for the effective length determinations $(\sigma \mathrm{EL})$ for the ligaments tested. Furthermore, the value for $r^{2}$, the fit of the quadratic polynomial equation to the force samples. Standard deviation for the force calculation when the maximal elongation in the tensile testing machine is applied in $\sigma F_{\max }$

\begin{tabular}{lcccccc}
\hline & $\begin{array}{c}L_{\text {NEUTRAL }} \\
(\mathrm{mm})\end{array}$ & $\begin{array}{c}L_{\mathrm{ZF}} \\
(\mathrm{mm})\end{array}$ & $\begin{array}{c}\sigma \mathrm{EL} \\
(\mathrm{mm})\end{array}$ & $\begin{array}{c}r^{2} \\
\left(\mathrm{~N}^{2}\right)\end{array}$ & $\begin{array}{c}F_{\max } \\
(\mathrm{N})\end{array}$ & $\begin{array}{c}\sigma F_{\max } \\
(\mathrm{N})\end{array}$ \\
\hline RCP & 31.94 & 36.92 & 0.078 & 1.18 & 115.4 & 4.3 \\
RLPp & 18.20 & 17.14 & 0.078 & 0.56 & 58.6 & 5.2 \\
RLPd & 16.12 & 15.61 & 0.078 & 1.13 & 43.4 & 3.8 \\
TCP & 18.18 & 16.48 & 0.078 & 0.74 & 92.2 & 6.3 \\
RTD & 21.15 & 19.66 & 0.078 & 0.07 & 39.2 & 2.3 \\
\hline
\end{tabular}


reports on direct force measurements (buckle-type transducers, implantable force transducers, etc.) or indirect measurements (Ahmed et al., 1987; Barnes and Pinder, 1974; Cummings et al., 1991; Huberti et al., 1984; Komi et al., 1987; Takai et al., 1991; Xu et al., 1990). This study has shown that preconditioning affects the force estimates considerably, as a consequence of the increase of the zero-force length and probably also due to a prolonged 'toe' region in the force-elongation curve. As is suggested in the literature, the forces that are estimated in the preconditioned ligament are lower than those estimated for non-preconditioned ligaments (Butler et al., 1978; Fung, 1972; Woo et al., 1983, 1986). Depending on the amount of effective elongation, these differences can be large enough to result in considerably different force estimates and as a consequence to influence conclusions about the functional importance of the structures considered. Hence, whether or not preconditioning should be applied to ligaments depends on the kind of situation that is to be simulated in an experiment. The susceptibility of the force values to preconditioning suggests that in vivo ligament forces may vary considerably due to the state of preconditioning of a ligament.

Acknowledgement - The authors gratefully acknowledge the cooperation of A. Lemmens, M.D. (Institute of Radiodiagnostics, University of Nijmegen) and $W$. van de Wijdeven (Institute of Orthopaedics) in parts of the experimental procedure.

\section{REFERENCES}

Ahmed, A. M., Hyder, A., Burke, D. L. and Chan, K. H. (1987) In-vitro ligament tension pattern in the flexed knee in passive loading. $J$. orthop. Res. 5, 217-230.

An, K.-N., Berglund, L., Cooney, W. P., Chao, E. Y. S. and Kovacevic, N. (1990) Direct in vivo tendon force measurement system. J. Biomechanics. 23, 1268-1271.

Barnes, G. R. G. and Pinder, D. N. (1974) In vivo tendon tension and bone strain measurement and correlation. J. Biomechanics 7, 35-42.

Barry, D. and Ahmed, A. M. (1986) Design and performance of a modified buckle transducer for the measurement of ligament tension. $J_{,}$biomech. Engng 108, 149-152.

Butler, D. L., Noyes, F. R. and Grood, E. S. (1978) Measurement of the mechanical properties of ligaments. In CRC Handbook of Engineering in Medicine and Biology (Edited by Feinberg, B. N. and Fleming, D. G.), Sect. B., Vol. I, pp. 279-314. CRC Press, Boca Raton.

Cummings, J. F., Holden, J. P., Grood, E. S., Wroble, R. R., Butler, D. L. and Schafer, J. A. (1991) In-vivo measurement of patellar tendon forces and joint position in the goat model. In Trans. 37th Annual Meeting of the ORS, p. 601 . ORS, Anaheim, California.

Fung, Y. C. (1972) Stress-strain history relations of soft tissues in simple elongation. In Biomechanics: its founda- tions and objectives (Edited by Fung Y. C., Perrone, N. and Anliker, M.). Prentice-Hall, Englewood Cliffs.

Huberti, H. H., Hayes, W. C., Stone, J. L. and Shybut, G. T. (1984) Force ratios in the quadriceps tendon and ligamentum patellae. J. orthop. Res. 2, 49-54.

Komi, P. V., Salonen, M., Järvinen, M. and Kokko, O. (1987) In vivo registration of achilles tendon forces in man. $I$. Methodological Development. Int. J. Sports Med. 8, 3-8. Lange, A. de, Huiskes, R. and Kauer, J. M. G. (1990) Wristjoint ligament length changes in flexion and deviation of the hand: an experimental study. J. orthop. Res. 8, 722-730.

Lange, A. de, Kauer, J. M. G. and Huiskes, R. (1985) The kinematical behavior of the human wrist joint: a roentgenstereophotogrammetric analysis. J. orthop. Res. 3, 56-64.

Lewis, J. L., Lew, W. D. and Schmidt, J. (1982) A note on the application and evaluation of the buckle transducer for knee ligament force measurement. J. biomech. Engng 104, 125-128.

Savelberg, H. H. C. M., Kooloos, J. G. M., Huiskes, R. and Kauer, J. M. G. (1992) Stiffness of the ligaments of the human wrist joint. $J$. Biomechanics 25, 369-376.

Savelberg, H. H. C. M., Kooloos, J. G. M., Lange, A. de, Huiskes, R. and Kauer, J. M. G. (1991) Human carpal ligament recruitment in relation to three-dimensional carpal kinematics. J. orthop. Res. 9, 693-704.

Selvik, G. (1974) A Roentgen stereophotogrammetric method for the study of the kinematics of the skeletal system. Doctoral dissertation, University of Lund, Sweden; reprinted as Acta Orthop. Scand. 60, (Suppl. 232), 1-51, 1989.

Takai, S., Adams, D. J., Livesay, G. A. and Woo, S. L.-Y. (1991) Determination of loads in the human anterior cruciate ligament. In Trans. 37th Annual Meeting of the ORS, p. 235. ORS, Anaheim, California.

Viidik, A. (1973) Functional properties of collagenous tissues. Int. Rev. Conn. Tissue Res. 6, 127-215.

Viidik, A. (1980) Mechanical properties of parallel-fibred collagenous tissues. In Biology of Collagen (Edited by Viidik, A.) pp. 237-255. Academic Press, London.

Woo, S. L.-Y., Gomes, M. A., Seguchi, Y., Endo, C. M. and Akeson, W. H. (1983) Measurement of mechanical properties of ligament substance from a bone-ligament-bone preparation. J. orthop. Res. 1, 22-29.

Woo, S. L.-Y., Orlando, C. A., Camp, J. F. and Akeson, W. H. (1986) Effect of postmortem storage by freezing on ligament tensile behavior. J. Biomechanics 19, 399-404.

Woo, S. L.-Y., Orlando, C. A., Gomes, M. A., Frank, C. B. and Akeson, W. H. (1986) Tensile properties of the medial collateral ligament as a function of age. J. orthop. Res. 4, 133-141.

Xu, W. S., Glos, D. L., Butler, D. L., Stouffer, D. C. and Grood, E. S. (1990) Analytic sensitivity studies of implantable force transducer in goat patellar tendon. Proc. 1st World Congress of Biomechanics, San Diego, California, p. 321 . 